\title{
A Learner-Engaging Reading Lesson
}

\section{Laxman Gnawali, PhD}

Teaching reading skill in the EFL classroom in Nepal and other countries with similar contexts is often a teacher-dominant phenomenon. Allowing and facilitating learners to take charge of the interactions with the text cannot only make lessons more interesting but prepare the learners to be in a position to develop independent reading skills for real life situations. This lesson illustrates the teaching of reading in which learners are actively engaged in the whole process while the teacher facilitates the process.

Proficiency Level: Intermediate to Advanced

Age Group: Late-teens to Adults

Class Time: 90 minutes

Objectives: By the end of this lesson, students will have: 1 . shared their personal opinions and experiences relating to socialization, 2. explored the text with a range of comprehension tasks, 3. completed tasks on grammar and vocabulary and participated in the group discussion, 4. engaged in different classroom dynamics for maximum interaction and sharing.

In the lesson, learners read the text, complete the tasks based on the text, and share their ideas relating it to their real-life experiences. They are engaged in an open discussion with their partners on upbringing and male-female behavior differences, and finally share their outcomes with the whole class.
Resources: Hand-outs and worksheets

\section{Procedure}

1) Scene setting (10 minutes)

Start by sharing that men and women behave in different ways with your own examples. Then, distribute the worksheet copies and ask students to read the questions in Task $\mathrm{A}$ and think of their own responses. Once the students indicate they are ready, ask the same questions aloud and hold a brief discussion based on their responses. Make sure that students are aware of the real-world context related to socialization before moving on.

2) Pre-teach vocabulary (10 minutes)

Divide students in pairs. Ask them to look at the words in Task B and discuss their meanings. Allow them to use mobiles phones for looking up the 
meaning of these words. Also, ask them to make sentences using these words. Once most pairs seem ready, hold a discussion on the meanings of each word, giving a sample sentence for each. If students have difficulties with particular words, you may need to provide the meanings. At the end, concept-check by asking questions like: How sturdy is this building? How permissive are your parents?

3) Extensive task (10 minutes)

After the scene setting and the discussion on the new vocabulary, students need to be led into the reading passage but cautiously, so an extensive task (a task which is obvious and easy to complete by reading along the lines) will be useful at this stage. Ask students to works in pairs and go through the first two paragraphs of the passage and answer the questions in Task C. Remember in this model of reading, you as a teacher are not expected to read and explain the passage for the students at all, unless the majority has a problem in understanding the text. Once the pairs are ready, lead a discussion on the answers with the whole class. Indicate which particular answer is correct and why.

4) Intensive tasks $(20+10+15$ mins $)$

a. Get students to work in pairs again and read the whole passage and do Task D 1. Once all pairs are ready, hold a brief discussion to decide which answers are appropriate and why. While the whole class discussion is going on, allow students to differ and let them justify their own answers. As above, you will provide the answers and explain the text if and only if most students do not seem to have understood the text.

b. Ask students to read the whole passage and find the original words from Paragraph 4 for the synonyms listed in Task D 2. Follow the same process of pair work, followed by a whole class discussion. Allow variations in the answer where appropriate. This type of discussion on the answers will be an opportunity for meaningful interactions for the students.

c. Ask students to work individually and list as many adjectives as they can from the passage. Each student compares his/her list with their neighbour's and develops a common list. This will be followed by a whole class discussion. As the class of words can change depending upon where they occur, the students will differ in their opinion about which word is an adjective and which is not. Explain where there is a difference of opinion to establish what is correct.

\section{5) Text related activity (15 mins)}

Get students to work in pairs again and share their opinions with each other on the issue raised by the questions. Once all pairs report they are ready, get voluntary pairs to share what they have decided.

If the society did not put pressure of how either sex should behave, what would be the social scenario? 


\section{A note on the activity}

This model of activity has been used in EFL teacher education programs in Nepal to help the trainees realize that a reading lesson is a reading opportunity for students, not for teachers. In order to develop confidence in their ability to read, students need to be given easier tasks (expensive tasks), which the weakest ones can complete before they engage in more indepth ones (intensive tasks). Before pushing them to whole class discussion, students need to be allowed to work on the task in pairs and then in small groups. Following the principle of schema activation, a scene setting at the beginning prepares students to be aware of the theme and its connection to the real world. The text-related activity at the end allows students to share their overall understanding on the concept of the text without going back to the text.

\section{Reference}

Gardner, P. S. (2005). Reading, writing, and critical thinking (2nd ed.). Cambridge: Cambridge University Press.

\section{Contributor}

A/Professor, Laxman Gnawali, PhD, teaches in Kathmandu University, School of Education, Lalitpur. Dr. Gnawali is the senior-vice president of NELTA and former deputy editor-inchief of Journal of NELTA. His research interests include language pedagogy, teacher professional development and professional networking.

\section{Appendix 1}

\section{Learning to behave}

How do we learn society's standards about appropriate behavior for each sex? Socialization is the general term used to describe the process of learning social roles. Most differences between females and males are learned through family interactions, socialization in schools, and the mass media. (1)

Social learning theory holds that children are rewarded for conforming to their parents' expectations and are punished for behavior that meets with disapproval. Thus, Johnny's parents beam with pride when he shows prowess on the basketball court, but gasp with horror if he displays an interest in becoming a dancer. Johnny learns to act 'like a boy' in order to please his parents. (2)

The process of differential treatment of girls and boys begins the minute children are born. Adults describe infant girls as 'delicate', 'sweet', or 'dainty' and hold them more carefully. By contrast, boys are perceived as more active and are described as 'bouncing' 'sturdy' or 'handsome'. As toddlers and preschoolers, children learn that baseball and trucks are for boys while dolls and 'dressing up' are for girls. (3) 
A study by Judith G. Tudiver demonstrated the differential socialization of preschool age children. Both mothers and fathers tended to be permissive and supportive with daughters, but did not feel that daughters needed to achieve or perform. However, parents of sons stressed the importance of achievement and independence. Fathers, in particular, were extremely concerned about socializing sons into a rather rigid definition of the masculine role. Tudiver concludes that 'a great deal of pressure' is associated with the socialization of sons, which "probably reflects the high value associated with being male in our society". (4)

Children and adolescents are influenced by the role models available in a society. If they see that most doctors, police officers, and U.S. Senators are male, while most nurses, secretaries, and early childhood teachers are female, they will begin to draw conclusions about which jobs are for them and which are not. 'Real life' role models affect children's thinking; so, too, do the role models presented in literature (including comics and children's books), film and television. (5)

(From Gardner, 2005)

\section{Appendix 2}

\section{A. Read these questions and think of your own answers.}

a. How did you know you should behave in a certain way because you are a boy or a girl?

b. Do you sometimes behave in a way that the society does not expect you to? How have people reacted to such behaviour?

B. Discuss the meanings of these words with your partner and make a sentence for each.

beam, prowess, dainty, sturdy, permissive, conform

\section{Do the tasks as instructed.}

1. Read the first two paragraphs and discuss possible answers with your partner.

a. What are the sources of learning about male female differences?

b. How do Johnny's parents react when he shows interest in dancing?

2. Now read the passage again and answer these questions. 